Hong Zhou / IOSR Journal of Engineering (IOSRJEN)

www.iosrjen.org

ISSN : 2250-3021

Vol. 2 Issue 2, Feb.2012, pp. 234-246

\title{
Transient temperature rises in a sandwich-structured composite induced by a dithering or rotating laser beam
}

\author{
Hong Zhou* \\ Department of Applied Mathematics \\ Naval Postgraduate School \\ Monterey, CA 93943-5216, U.S.A.
}

\begin{abstract}
Numerical solutions are provided for a transient temperature rise in a composite sandwich structure that is induced by a dithering or rotating laser beam. Here we consider using E-glass or C-glass fibers as skin materials whereas the core can be selected from a variety of materials including balsa wood, honeycomb, cork and C-foam. Our results provide insights in engineering sandwich-structured composite as heat shields. More specifically, it is shown that (1) carbon fibers are better skin materials than E-glass fibers; (2) sandwichstructured composite with carbon fiber skin and honeycomb core is most promising.
\end{abstract}

Keywords: rotating or dithering Gaussian laser beam; non-homogeneous heat equation; composite sandwich structure

\section{INTRODUCTION}

Direct energy laser weapons deliver high-intensity beams to an object and can quickly destroy or burn it. In order to protect important objects, such as Navy ships and missiles, one possible counter measure is to use materials of composite sandwich structure to enhance damage tolerance of the object or let the object rotate or shake to reduce the maximum temperature rise. The main purpose here is to investigate the temperature rise of a composite sandwich structure induced by a rotating or dithering laser beam and find ways to reduce or avoid laser weapon damages.

The study of the temperature rise induced by a laser beam is not a new subject. A lot of research have been devoted to the theoretical and numerical modeling of temperature profiles induced by laser radiation in solids (Araya and Gutierrez, 2006; Bertolotti and Sibilia., 1981; Burgener and Reedy, 1982; Calder and Sue, 1982; Cline and Anthony, 1977; Lax, 1977 and 1978; Moody and Hendel, 1982; Sanders, 1984; Sistaninia et al., 2009) and temperature distributions in a two-layer structure by a scanning laser beam (Burgener and Reedy, 1982). Recently we have given a detailed study of the temperature rise induced by a rotating or dithering laser beam on a semi-infinite domain (Zhou, 2011a), a solid with finite geometry (Zhou and Tan, 2011; Tan and Zhou, 2012), and a two-layer structure (Zhou, 2011b; Zhou, 2012).

In this paper we extend our earlier studies to a sandwich-structured composite, which is a special class of composite materials and is fabricated by attaching two stiff but thin skins to a lightweight but thick core. The core material normally has low strength, but its higher thickness provides the sandwich-structured composite with high bending stiffness and overall low density. Thicker core material leads to stronger sandwich-structured composite. Commonly-used core materials include balsa wood, honeycombs, cork and C-foam whereas widelyused skin materials are E-glass fibers and Carbon fibers. Sandwich-structured composite materials are becoming popular in high-performance products that need to be lightweight, yet strong enough to endure harsh loading conditions such as boat hulls, bicycle frames, sports car bodies and spacecraft components. We would like to investigate the temperature rise induced by a dithering or rotating laser beam on a sandwich-structured composite and compare the performance of different materials when used as heat shields.

We organize our paper as follows. In Sections 2-3 we present the modeling and numerical solutions of the temperature distributions in a three-dimensional composite sandwich structure induced by a dithering or rotating laser beam, respectively. Finally, conclusions are drawn in Section 4.

\section{MATHEMATICAL FORMULATIONS}

We first construct a time-dependent model of a three-dimensional composite sandwich structure made of one core material sandwiched between two thin layers of other materials. Laser beams are shone on the top surface of the sandwich structure. Figure 1 depicts a composite sandwich structure. We divide the finite structure into three regions: Region 1 is a thin layer of thickness $d_{1}$ in the $z$ direction, which is on a substrate of 


\section{Hong Zhou / IOSR Journal of Engineering (IOSRJEN)}

www.iosrjen.org

ISSN : 2250-3021

Vol. 2 Issue 2, Feb.2012, pp. 234-246

dissimilar material of thickness $d_{2}$ (Region 2), and Region 3 is another thin layer of thickness $d_{3}$ at the bottom of the structure. The materials in both Region 1 and Region 3 are the same.

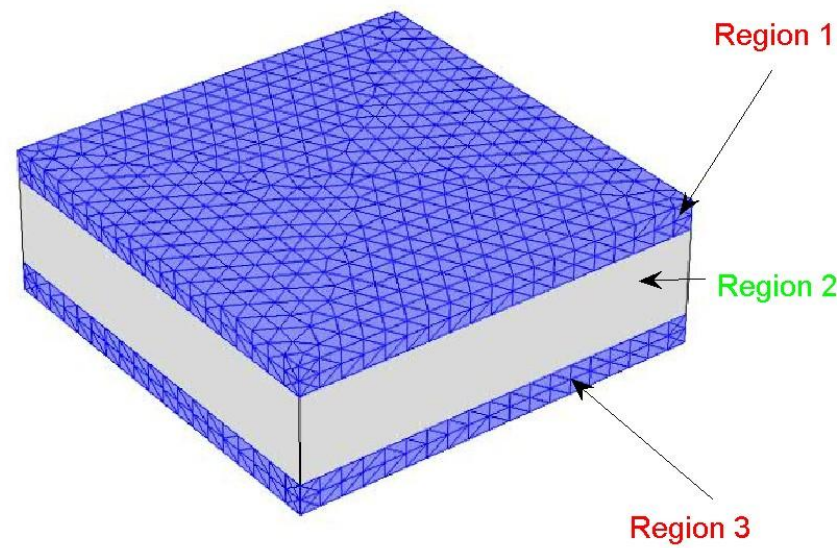

Figure 1: A schematic diagram of a three-dimensional composite sandwich structure.

Mathematically, the temperature distribution in the composite sandwich structure can be modeled as follows. In Region 1, the governing equation is

$$
\frac{\partial u_{1}}{\partial t}=\alpha_{T, 1}\left(\frac{\partial^{2} u_{1}}{\partial x^{2}}+\frac{\partial^{2} u_{1}}{\partial y^{2}}+\frac{\partial^{2} u_{1}}{\partial z^{2}}\right)+\frac{\alpha_{T, 1}}{K_{T, 1}} q(x, y, z, t),
$$

where $u_{1}(x, y, z, t)$ denotes the temperature rise at position $(x, y, z)$ and time $t, \alpha_{T, 1}$ is the thermal diffusivity of the material in Region $1, K_{T, 1}$ is the thermal conductivity, and $q(x, y, z, t)$ is the energy distribution of the moving laser beam. In the simulations presented in this paper we model the distribution of a dithering or rotating Gaussian beam as

$$
q(x, y, z, t)=f(x, y, t) \delta\left(z-z_{0}\right) .
$$

Here $f(x, y, t)$ is given by

$$
\begin{aligned}
& f(x, y, t)=\frac{I_{0}}{2 \pi d^{2}} \exp \left[-\frac{\left(x-x_{c}(t)\right)^{2}+\left(y-y_{c}(t)\right)^{2}}{2 d^{2}}\right], \\
& x_{c}(t)=x_{0}+a \cos \frac{2 \pi t}{T}, \quad x_{0}=\frac{L_{x}}{2}, \\
& y_{c}(t)=y_{0}+b \sin \frac{2 \pi t}{T}, \quad y_{0}=\frac{L_{y}}{2},
\end{aligned}
$$

where $\left(x_{c}(t), y_{c}(t), z_{0}\right)$ is the position of the dithering or rotating Gaussian beam, $\left(x_{0}, y_{0}, z_{0}\right)$ is the initial position of the laser beam, $I_{0}$ is the intensity of the laser beam, $r_{0}$ is the effective radius of the laser beam, $k$ is a constant used for the Gaussian model and $\delta\left(z-z_{0}\right)$ is the Dirac delta function. Equation (3) represents a 


\section{Hong Zhou / IOSR Journal of Engineering (IOSRJEN)}

Vol. 2 Issue 2, Feb.2012, pp. 234-246

rotating laser beam when $a=b$ and a dithering beam when either $a$ or $b$ is zero. When $a=b=0$, equation (3) simply represents a non-moving Gaussian beam. In Region 2, the equation for the temperature rise $u_{2}(x, y, z, t)$ where the material has the thermal diffusivity $\alpha_{T, 2}$ and thermal conductivity $K_{T, 2}$ is

$$
\frac{\partial u_{2}}{\partial t}=\alpha_{T, 2}\left(\frac{\partial^{2} u_{2}}{\partial x^{2}}+\frac{\partial^{2} u_{2}}{\partial y^{2}}+\frac{\partial^{2} u_{2}}{\partial z^{2}}\right)
$$

In Region 3, the equation for the temperature rise $u_{3}(x, y, z, t)$ is

$$
\frac{\partial u_{3}}{\partial t}=\alpha_{T, 3}\left(\frac{\partial^{2} u_{3}}{\partial x^{2}}+\frac{\partial^{2} u_{3}}{\partial y^{2}}+\frac{\partial^{2} u_{3}}{\partial z^{2}}\right)
$$

At the interfaces between the materials, we require that the energy is conserved for heat flow across the interfaces:

$$
\begin{aligned}
& K_{T, 1} \frac{\partial u_{1}}{\partial z}=K_{T, 2} \frac{\partial u_{2}}{\partial z} \quad \text { at the interface between Regions } 1 \text { and } 2 \\
& K_{T, 2} \frac{\partial u_{2}}{\partial z}=K_{T, 3} \frac{\partial u_{3}}{\partial z} \quad \text { at the interface between Regions } 2 \text { and } 3
\end{aligned}
$$

The initial condition for $u_{1}(x, y, z, t), u_{2}(x, y, z, t), u_{3}(x, y, z, t)$ is zero which assumes that the composite sandwich structure has the same temperature as the ambient initially. The boundary conditions at the air/material interface impose that the sandwich structure is insulated at the edges. The boundary conditions reflect the assumption that no energy escapes into the ambient at the air/material interface. This is a good approximation for most materials under consideration because heat flow by conduction through the material is usually much bigger than heat loss by radiation or convection at the air/material interface.

For the top (Region 1) and bottom (Region 3) skins of the composite sandwich structure, the materials are either E-glass fibers or carbon fibers. E-glass or electrical grade glass is a lightweight, extremely strong, low-cost and non-flammable material. It is also relatively insensitive to moisture and has good electrical insulation. Common uses of E-glass include surfboards, sports cars, boats, flat roofs, water tanks and pipes. Compared to E-glass fibers, carbon fibers are relatively expensive similar fibers. They have high flexibility, high tensile strength, low weight, high temperature tolerance and low thermal expansion. Carbon fibers are very popular in aerospace, civil engineering, military, and automobile. An E-glass/carbon fiber component is typically of a thin "shell'" construction, sometimes filled on the inside with structural core, as in the case of surfboards.

As for the core (Region 2), we choose several materials: balsa wood, Nomex honeycomb, cork and $C$ foam. Here we give a very brief introduction to each of these four materials. (1) Balsa wood is often used as a core material in composites, for example, many wind turbines are made partially of balsa wood. It is also used in the floor pan of the luxury sports car Chevrolet Corvette Z06 sandwiched between two sheets of carbon fiberreinforced polymer. (2) Nomex honeycomb is a lightweight, flame resistant material originally developed in the early 1960 s by Dupont Chemical for the aviation industry. It has excellent thermal, chemical, and radiation resistance and is widely used in firefighting equipment. (3) Cork is an impermeable, buoyant material that is extracted primarily from the Cork Oak trees. Cork is used as bottle stoppers, floor and wall tiles, bricks for the outer walls of houses, and a core material in sandwich composite construction. It is also used in spacecraft heat shields. (4) C-foam is a structural material that is inexpensive, lightweight, fire-resistant, and impact-absorbing. C-foams are currently being developed for many uses including fire-resistant ship decking, noise and impact mitigation for aircraft, structural panels and firewalls for automobiles.

The thermal properties of the skin and core materials are listed in Table 1 (Wang et al. 2007; Silva et al. 2005).

\section{NUMERICAL SOLUTIONS}

In this section we will compare the performance of each core material combined with two different skin materials: E-glass fibers or Carbon fibers. We select the commercial software COMSOL to solve the equations (1)-(6) with the given initial and boundary conditions. COMSOL is a finite-element-based software which can be exploited to solve our model equations efficiently. 


\section{Hong Zhou / IOSR Journal of Engineering (IOSRJEN)}

www.iosrjen.org

ISSN : 2250-3021

Vol. 2 Issue 2, Feb.2012, pp. 234-246

We consider a sandwich structure where the core has thickness $6 \mathrm{~mm}$ and cross section dimension $304.8 \mathrm{~mm} \times 304.8 \mathrm{~mm}$ and the top and bottom skins are $0.5 \mathrm{~mm}$ thick. First we shine a Gaussian beam on the top surface of the sandwich structure where $I_{0}=500 \mathrm{~W}, d=0.0025 \mathrm{~m}, a=b=0, L_{x}=L_{y}=0.3048 \mathrm{~m}$ in equation (3).

Table 1: Thermal properties of various materials

\begin{tabular}{|c|c|c|c|c|c|c|}
\hline Property Name & $\begin{array}{l}\text { E-glass } \\
\text { fiber }\end{array}$ & $\begin{array}{l}\text { Carbon } \\
\text { fiber }\end{array}$ & $\begin{array}{l}\text { Balsa } \\
\text { wood }\end{array}$ & $\begin{array}{l}\text { Nomex } \\
\text { honeycomb }\end{array}$ & Cork & C-foam \\
\hline $\begin{array}{l}\text { Heat Capacity } \\
\text { (or Specific Heat) } \\
C_{p} \quad \text { (unit: } \\
\mathrm{J} /(\mathrm{kg} * \mathrm{~K}))\end{array}$ & 900 & 676 & 1700 & $\begin{array}{l}1172 \\
\sim 1340\end{array}$ & 350 & 1260 \\
\hline $\begin{array}{l}\text { Density } \rho \\
\text { (unit: } \mathrm{Kg} /\left(\mathrm{m}^{\wedge} 3\right) \text { ) }\end{array}$ & 2580 & 1760 & 130 & 1100 & 150 & 480 \\
\hline $\begin{array}{l}\text { Thermal } \\
\text { Conductivity } K_{T} \\
\text { (unit: } \mathrm{W} /(\mathrm{m} * \mathrm{~K}) \text { ) }\end{array}$ & 1.3 & 84 & $\begin{array}{l}0.03 \\
\sim 0.07\end{array}$ & 0.175 & 0.045 & $\begin{array}{l}0.033 \\
\sim 0.050\end{array}$ \\
\hline $\begin{array}{l}\text { Thermal Diffusivity } \\
\alpha_{T}=\frac{K_{T}}{\rho \cdot C_{p}} \\
\text { (unit: } \mathrm{m}^{\wedge} 2 / \mathrm{s} \text { ) }\end{array}$ & $\begin{array}{l}5.5986 \\
\times 10^{-7}\end{array}$ & $\begin{array}{l}7.0602 \\
\times 10^{-5}\end{array}$ & $\begin{array}{l}1.3575 \times 10^{-7} \sim \\
3.1674 \times 10^{-7}\end{array}$ & $\begin{array}{l}1.1872 \times 10^{-7} \sim \\
1.3574 \times 10^{-7}\end{array}$ & $8.5714 \times 10^{-7}$ & $\begin{array}{l}5.4563 \times 10^{-8} \sim \\
8.2672 \times 10^{-8}\end{array}$ \\
\hline
\end{tabular}

Figures 2-5 show the temperature rises in the sandwich structure with different materials at time $t=6 s$. More specifically, in the left column of Figure 2 the temperature rise on an E-glass/balsa wood composite is shown whereas the right column depicts the temperature rise on an E-glass/honeycomb composite. Hitting by a Gaussian beam for 6 seconds, the E-glass/balsa wood composite reaches a maximum temperature of about $3.7 \times 10^{4} \mathrm{~K}$ on the incident face whereas the E-glass/honeycomb composite has a maximum temperature of about $2.5 \times 10^{4} \mathrm{~K}$ on the incident face. This indicates that using different core materials can make a big difference in reducing maximum temperature rise. Figure 3 shows the temperature rise of the E-glass/cork composite and the E-glass/C-foam composite after hitting by a Gaussian beam for 6 seconds. The E-glass/cork composite obtains a maximum temperature $4.0 \times 10^{4} \mathrm{~K}$ on the incident face whereas the maximum incident face temperature of E-glass/C-foam rises to $3.4 \times 10^{4} \mathrm{~K}$.

Figures 4-5 are similar to Figures 2-3, where the skin material is replaced by carbon fibers. From Figures 4-5 we can see that the maximum temperature rise on the incident face is reduced significantly now in each composite sandwich structure (all about 4000K).

Of practical interest is the maximum temperature rise on the top/bottom surfaces (incident face and rear face) and the middle cross-section of the sandwich structure. We document our numerical results in Table 2. From Table 2, one can see that Carbon fibers are better skin materials than E-glass fibers. Moreover, the Carbon fiber/Nomex honeycomb sandwich structure has the best performance with smallest value of the maximum temperature rise. 
Hong Zhou / IOSR Journal of Engineering (IOSRJEN)

www.iosrjen.org

ISSN : 2250-3021

Vol. 2 Issue 2, Feb.2012, pp. 234-246
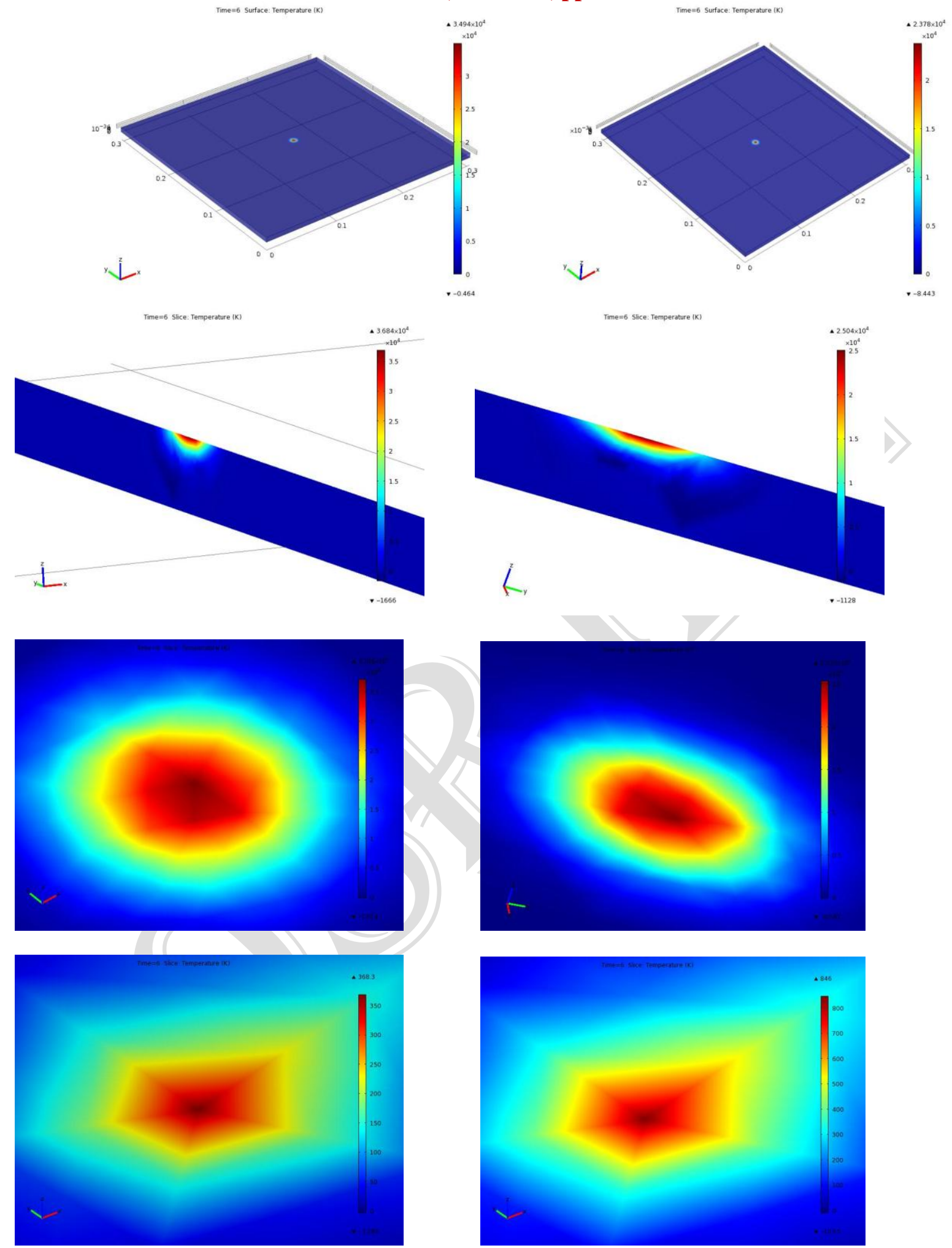

Figure 2: The temperature rise of a sandwich structure with E-glass fiber skins induced by a Gaussian beam. Left column: Balsa wood core; Right column: Nomex honeycomb core. Top row: 3-D view; Second row: a vertical slice through the center of the top surface; Third row: top surface; Fourth row: bottom surface. 
Hong Zhou / IOSR Journal of Engineering (IOSRJEN)

www.iosrjen.org

ISSN : 2250-3021

Vol. 2 Issue 2, Feb.2012, pp. 234-246
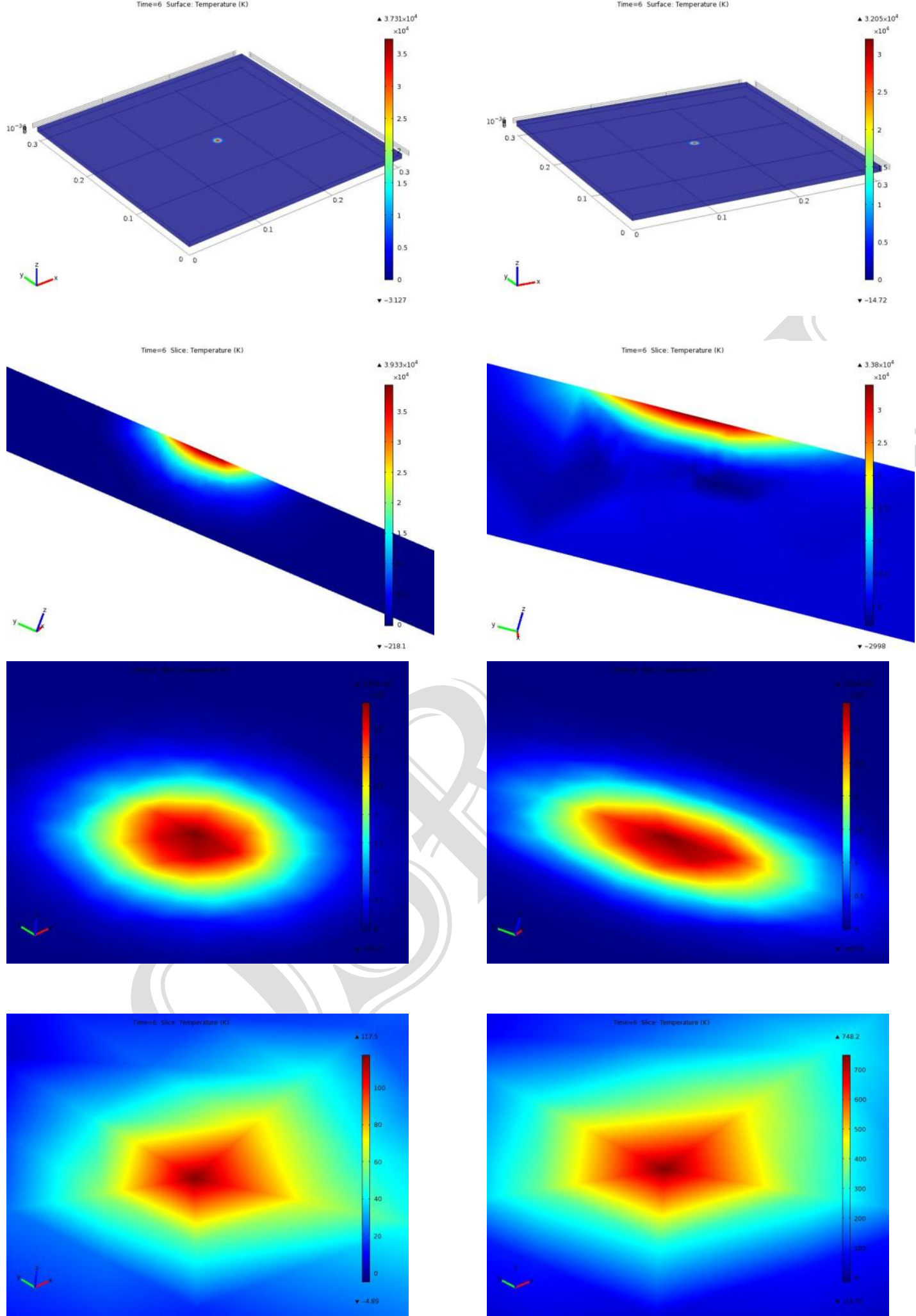

Figure 3: The temperature rise of a sandwich structure with E-glass fiber skins induced by a Gaussian beam. Left column: cork core; Right column: C-foam core. Top row: 3-D view; Second row: a vertical slice through the center of the top surface; Third row: top surface; Fourth row: bottom surface. 
Hong Zhou / IOSR Journal of Engineering (IOSRJEN)

www.iosrjen.org

ISSN : 2250-3021

Vol. 2 Issue 2, Feb.2012, pp. 234-246
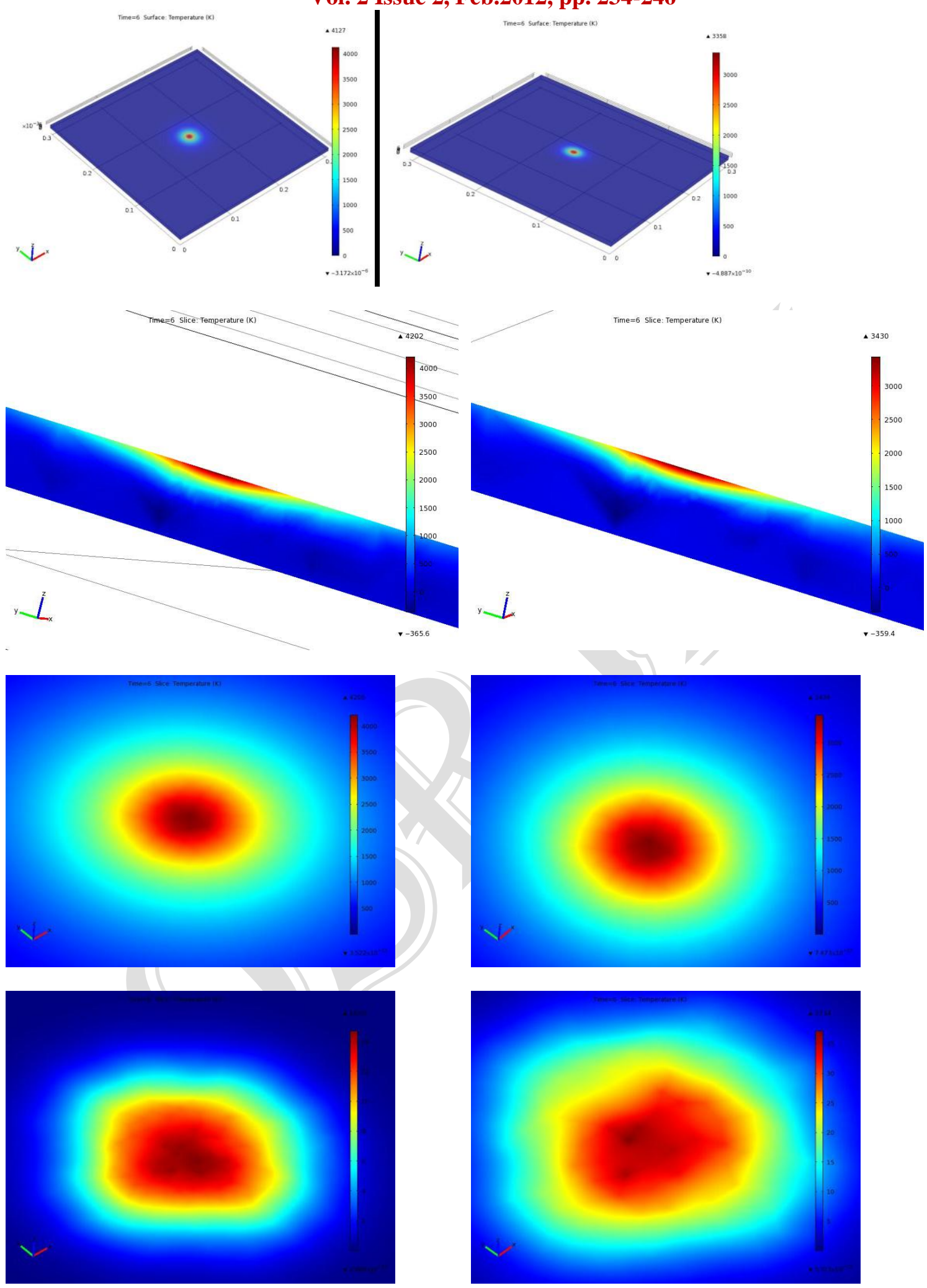

Figure 4: The temperature rise of a sandwich structure with Carbon fiber skins induced by a Gaussian beam. Left column: Balsa wood core; Right column: Nomex honeycomb core. Top row: 3-D view; Second row: a vertical slice through the center of the top surface; Third row: top surface; Fourth row: bottom surface. 
Hong Zhou / IOSR Journal of Engineering (IOSRJEN)

www.iosrjen.org

ISSN : 2250-3021

Vol. 2 Issue 2, Feb.2012, pp. 234-246
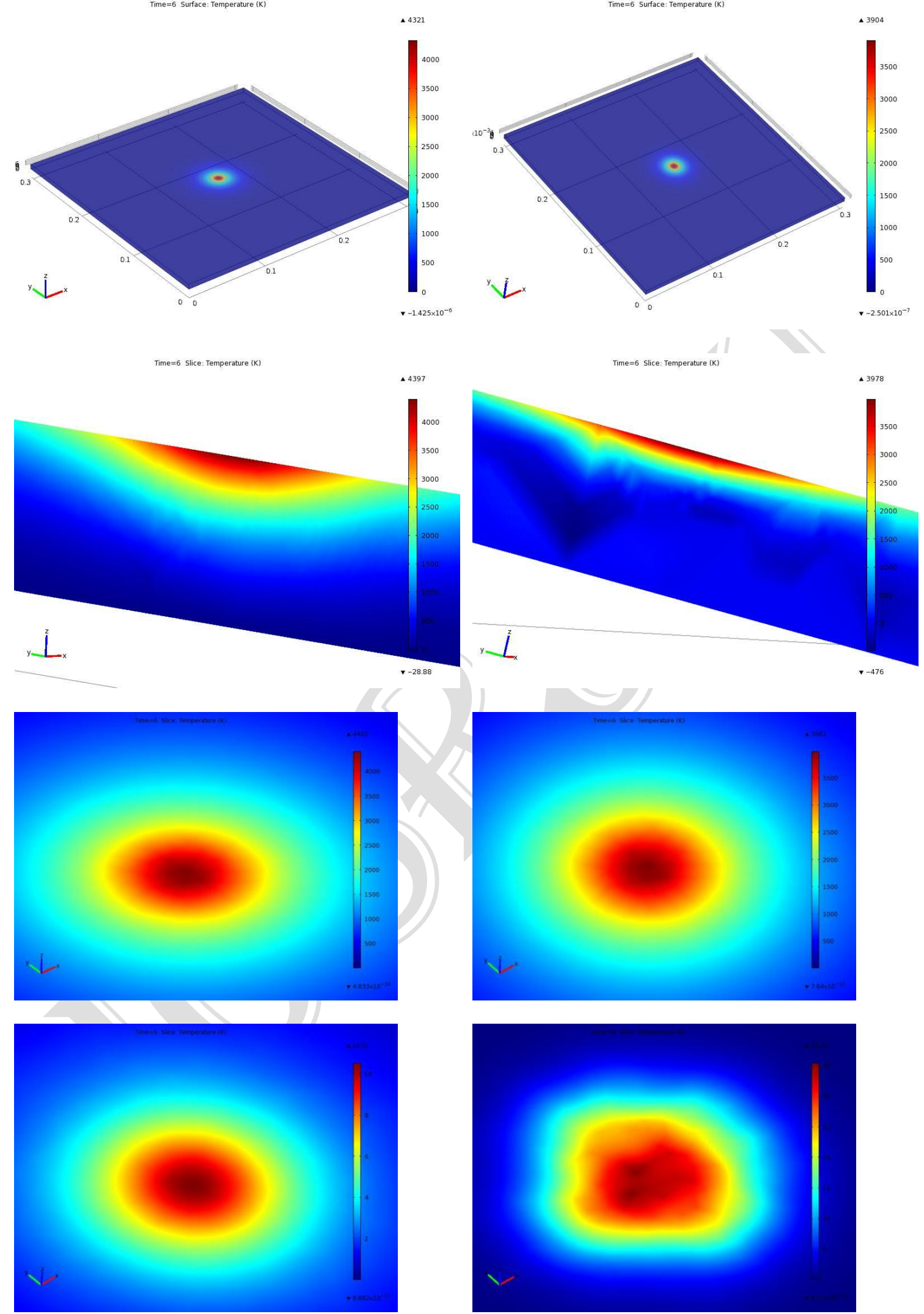

Figure 5: The temperature rise of a sandwich structure with Carbon fiber skins induced by a Gaussian beam. Left column: cork core; Right column: C-foam core. Top row: 3-D view; Second row: a vertical slice through the center of the top surface; Third row: top surface; Fourth row: bottom surface. 
Hong Zhou / IOSR Journal of Engineering (IOSRJEN)

www.iosrjen.org

ISSN : 2250-3021

Vol. 2 Issue 2, Feb.2012, pp. 234-246

Table 2: Maximum temperature rise on a sandwich structure induced by a Gaussian laser beam

\begin{tabular}{|l|l|l|l|l|}
\hline Skin material & Core material & $\begin{array}{l}T_{\max } \text { on the incident } \\
\text { face }(K)\end{array}$ & $\begin{array}{l}T_{\max } \text { on the } \\
\text { middle cross- } \\
\text { section }(K)\end{array}$ & $\begin{array}{l}T_{\max } \text { on the rear } \\
\text { face } \\
(K)\end{array}$ \\
\hline E-glass fiber & Balsa wood & $3.708 \times 10^{4}$ & 3993 & 368 \\
\hline E-glass fiber & Nomex honeycomb & $2.536 \times 10^{4}$ & 2293 & 846 \\
\hline E-glass fiber & Cork & $3.954 \times 10^{4}$ & 7463 & 117 \\
\hline E-glass fiber & C-foam & $3.409 \times 10^{4}$ & 3228 & 748 \\
\hline Carbon fiber & Balsa wood & 4206 & 612 & 14 \\
\hline Carbon fiber & Nomex honeycomb & 3434 & 411 & 37 \\
\hline Carbon fiber & Cork & 4400 & 1294 & 10 \\
\hline Carbon fiber & C-foam & 3982 & 472 & 35 \\
\hline
\end{tabular}

Next we study the temperature rise induced by a dithering laser beam. In formula (3) we choose $I_{0}=500 \mathrm{~W}, d=0.0025 m, a=0, b=0.05 m, L_{x}=L_{y}=0.3048 m, T=1 s$. In Figure 6 we show the temperature rise on the sandwich structure induced by the dithering beam where the materials are E-glass/Balsa wood and Carbon fiber/Balsa wood. The maximum temperature rise induced by a dithering beam on the incident face is $5753 \mathrm{~K}$ for E-glass/balsa wood composite and $1182 \mathrm{~K}$ for Carbon fiber/balsa wood composite. Again, Carbon fibers are better than E-glass as skin materials.

Figure 7 plots the temperature rise induced by a rotating laser beam with $I_{0}=500 \mathrm{~W}, d=0.0025 m, a=b=0.05 m, L_{x}=L_{y}=0.3048 m$ in expression (3). Now, the maximum temperature rise on the incident face drops further to $963 \mathrm{~K}$ for E-glass/balsa wood and $530 \mathrm{~K}$ for Carbon fiber/balsa wood.

Finally, we summarize the maximum temperature rise at the top/bottom surfaces and the middle crosssection of the sandwich structure for different materials in Table 3 for a dithering beam and Table 4 for a rotating beam, respectively. It is clear from these tables that carbon fiber/honeycomb sandwich-structured composite serves best as heat shield.

\section{CONCLUSIONS AND FUTURE WORK}

We have calculated the temperature rise induced by a rotating or dithering Gaussian laser beam for a composite sandwich structure. Our simulations indicate that carbon fibers are better skin materials than E-glass fibers and composite sandwich structure with carbon fiber skin and honeycomb core can serve extremely well as heat shields. More detailed studies on the optimal design of a composite sandwich structure are left for future exploration.

\section{ACKNOWLEDGEMENT}

We would like to thank Mr. Peter Morrison and the Office of Naval Research (ONR) for supporting this work. We also thank Joseph Puishys at United States Naval Academy and Dr. Robert Cozzens at Naval Research Laboratory for helpful discussions. 
Hong Zhou / IOSR Journal of Engineering (IOSRJEN)

www.iosrjen.org

ISSN : 2250-3021

Vol. 2 Issue 2, Feb.2012, pp. 234-246
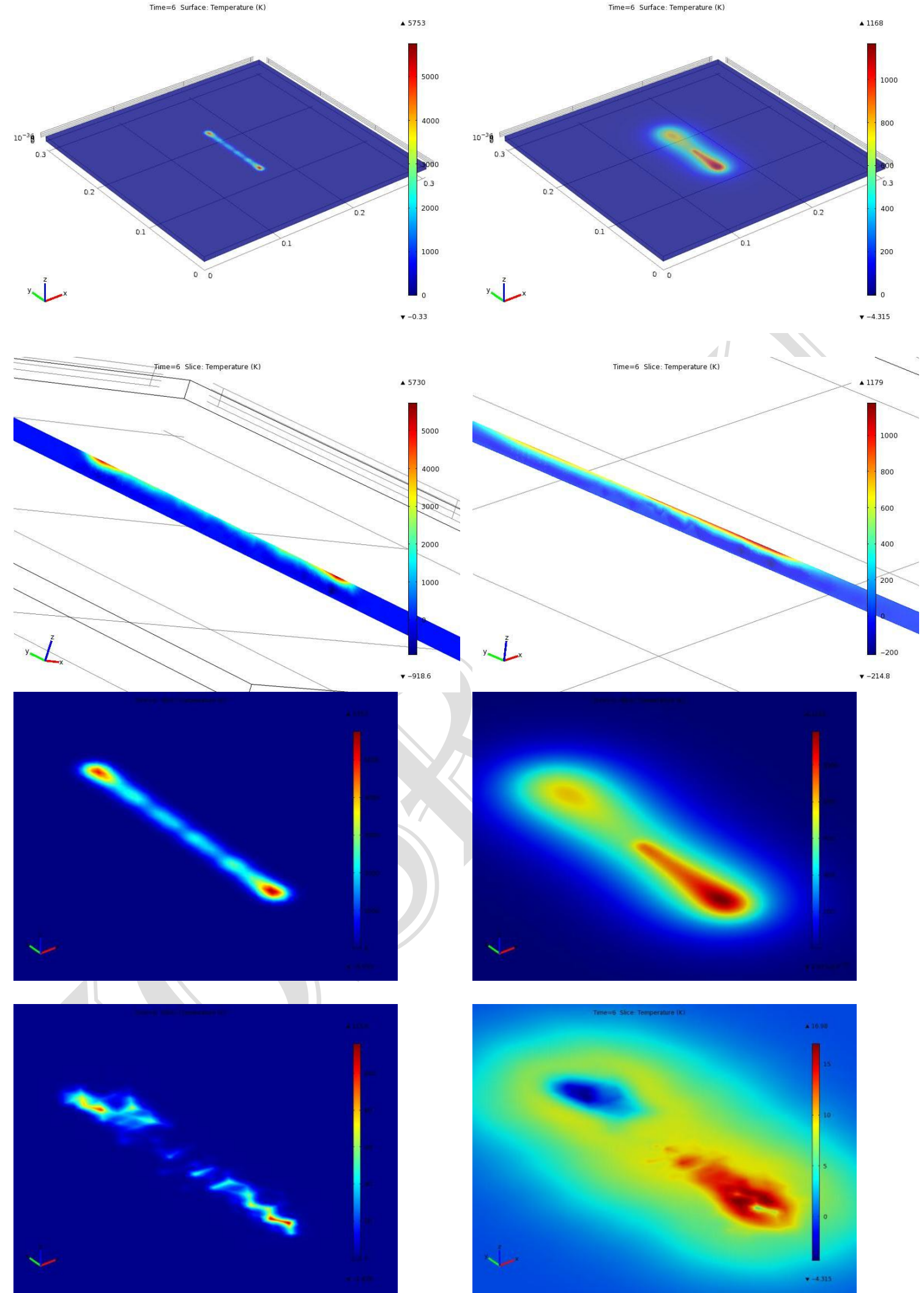

Figure 6: The temperature rise of a sandwich structure with Balsa wood core induced by a dithering Gaussian beam. Left column: E-glass skin; Right column: Carbon fiber skin. Top row: 3-D view; Second row: a vertical slice through the center of the top surface; Third row: top surface; Fourth row: bottom surface. 
Hong Zhou / IOSR Journal of Engineering (IOSRJEN)

www.iosrjen.org

ISSN : 2250-3021

Vol. 2 Issue 2, Feb.2012, pp. 234-246
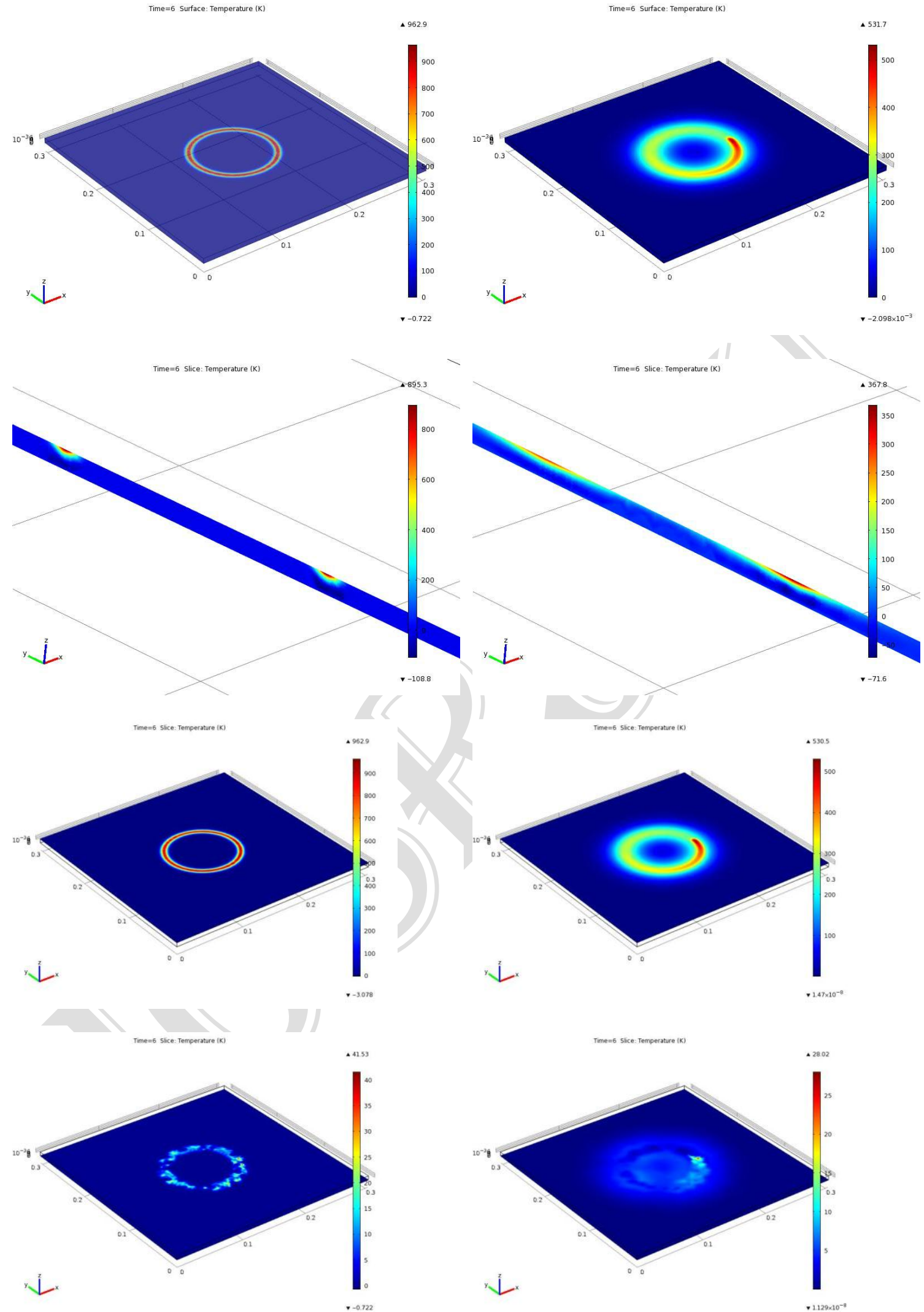

Figure 7: The temperature rise of a sandwich structure with Balsa wood core induced by a rotating Gaussian beam. Left column: E-glass skin; Right column: Carbon fiber skin. Top row: 3-D view; Second row: a vertical slice through the center of the top surface; Third row: top surface; Fourth row: bottom surface. 
Hong Zhou / IOSR Journal of Engineering (IOSRJEN)

www.iosrjen.org

ISSN : 2250-3021

Vol. 2 Issue 2, Feb.2012, pp. 234-246

Table 3: Maximum temperature rise on the sandwich structure induced by a dithering Gaussian laser beam

\begin{tabular}{|l|l|l|l|l|}
\hline Skin material & Core material & $\begin{array}{l}T_{\max } \text { on the incident } \\
\text { face } \\
(K)\end{array}$ & $\begin{array}{l}T_{\max } \text { on the } \\
\text { middle cross- } \\
\text { section }(K)\end{array}$ & $\begin{array}{l}T_{\max } \text { on the rear } \\
\text { face } \\
(K)\end{array}$ \\
\hline E-glass fiber & Balsa wood & 5753 & 876 & 115 \\
\hline E-glass fiber & Nomex honeycomb & 3686 & 505 & 282 \\
\hline E-glass fiber & Cork & 6090 & 1556 & 26 \\
\hline E-glass fiber & C-foam & 4869 & 589 & 356 \\
\hline Carbon fiber & Balsa wood & 1182 & 197 & 16 \\
\hline Carbon fiber & Nomex honeycomb & 862 & 126 & 45 \\
\hline Carbon fiber & Cork & 1268 & 369 & 6 \\
\hline Carbon fiber & C-foam & 1110 & 143 & 44 \\
\hline
\end{tabular}

Table 4: Maximum temperature rise on the sandwich structure induced by a rotating Gaussian laser beam

\begin{tabular}{|l|l|l|l|l|}
\hline Skin material & Core material & $\begin{array}{l}T_{\max } \text { on the incident } \\
\text { face }(K)\end{array}$ & $\begin{array}{l}T_{\max } \text { on the } \\
\text { middle cross- } \\
\text { section }(K)\end{array}$ & $\begin{array}{l}T_{\max } \text { on the rear } \\
\text { face } \\
(K)\end{array}$ \\
\hline E-glass fiber & Balsa wood & 963 & 195 & 41 \\
\hline E-glass fiber & Nomex honeycomb & 653 & 118 & 87 \\
\hline E-glass fiber & Cork & 1116 & 335 & 9 \\
\hline E-glass fiber & C-foam & 907 & 143 & 96 \\
\hline Carbon fiber & Balsa wood & 530 & 101 & 28 \\
\hline Carbon fiber & Nomex honeycomb & 313 & 58 & 48 \\
\hline Carbon fiber & Cork & 598 & 154 & 8 \\
\hline Carbon fiber & C-foam & 432 & 79 & 50 \\
\hline
\end{tabular}

\section{REFERENCES}

Araya, G., \& Gutierrez, G. (2006). Analytical solution for a transient, three-dimensional temperature distribution due to a moving laser beam, Int. J. Heat and Mass Transfer, 49, 4124-4131.

Asmar, N.H. 2004. Partial Differential Equations with Fourier Series and Boundary Value Problems, $2^{\text {nd }}$ edition, Prentice Hall, Upper Saddle River, New Jersey.

Bertolotti, M.., \& Sibilia, C. (1981). Depth and velocity of the laser-melted front from an analytical solution of the heat conduction equation, IEEE J. Quantum Electron., QE-17, 1980-1989.

Burden, R. L., \& Faires, J. D. 2005, Numerical Analysis, $8^{\text {th }}$ edition, Brooks/Cole, Boston.

Burgener, M. L., \& Reedy, R. E. (1982). Temperature distributions produced in a two-layer structure by a scanning cw laser or electron beam, Journal of Applied Physics, 53, 4357-4363.

Bush, A. W. 1992. Perturbation Methods for Engineers and Scientists, CRC Press, Boca Raton.

Calder, I. D., \& Sue, R. (1982). Modeling of cw laser annealing of multilayer structures, Journal of Applied Physics, 53, 7545-7550.

Cline, H. E., \& Anthony, T. R.. (1977). Heat treating and melting material with a scanning laser or electron beam, Journal of Applied Physics, 48, 3895-3900. 


\section{Hong Zhou / IOSR Journal of Engineering (IOSRJEN)}

www.iosrjen.org

ISSN : 2250-3021

Vol. 2 Issue 2, Feb.2012, pp. 234-246

Hayter, A. J. 2002. Probability and Statistics for Engineers and Scientists, Duxbury, Pacific Grove, California.

John, F. 1981. Partial Differential Equations, Springer, New York.

Lax, M. (1977). Temperature rise induced by a laser beam, Journal of Applied Physics, 48, 3919-3924.

Lax, M. (1978). Temperature rise induced by a laser beam II. The nonlinear case, Applied Physics Letter, 33, 786-788.

Moody, J. E., \& Hendel, R. H. (1982). Temperature profiles induced by a scanning cw laser beam, Journal of Applied Physics, 53, 4364-4371.

Sanders, D. J. (1984). Temperature distributions produced by scanning Gaussian laser beams, Applied Optics, 23, 30-35.

Silva, S.P., Sabino, M.A., Fernandes, E.M., Correlo, V.M., Boesel, L.F. \& Reis, R.L. (2005). Cork: properties, capabilities and applications, International Materials Review, 50(6), 345-365.

Sistaninia, Me., Sistaninia, Ma., \& Moeanodini, H. (2009). Laser forming of plates using rotating and dithering beams, Computational Materials Science, 45, 480-488.

Tan, T. (2010).Temperature rise induced by a rotating/dithering laser beam on a finite solid, Naval Postgraduate School, Master Thesis.

Tan, T. and Zhou, H. (2012) Numerical solution for a transient temperature distribution on a finite domain due to a dithering or rotating laser beam, International Journal of Operations Research and Information Systems, in press.

Wang, Z.L., Tang, D.W. and Zhang, W.G. (2007) Simultaneous measurements of the thermal conductivity, thermal capacity and thermal diffusivity of an individual carbon fibre, Journal of Physics D: Applied Physics, 40, 4686-4690.

Zhou, H. (2011a) Temperature rise induced by a rotating or dithering laser beam, Advanced Studies in Theoretical Physics, 5(10), 443-468.

Zhou, H. (2011b) Transient temperature distributions produced in a two-layer finite structure by a dithering or rotating laser beam, Fourteenth Annual Directed Energy Symposium Proceedings, 1416-1431.

Zhou, H. and Tan, T. (2011) Transient temperature distribution on a finite domain induced by a dithering or rotating laser beam, 2011 Directed Energy Systems Symposium Proceedings, 83-105.

Zhou, H. (2012) Temperature rise in a two-layer structure induced by a rotating or dithering laser beam, Journal of Mathematical and Computational Science, in press. 